\section{Atividades de controle do dengue na visão de seus agentes e da população atendida, São José do Rio Preto, São Paulo, Brasil}

\author{
Dengue control as viewed by agents \\ and the target population in São José \\ do Rio Preto, São Paulo, Brazil
}

\author{
Virgínia Baglini 1 \\ Eliane Aparecida Favaro 2 \\ Aline Chimello Ferreira 3 \\ Francisco Chiaravalloti Neto 2,3 \\ Adriano Mondini 2 \\ Margareth R. Dibo 3 \\ Angelita A. C. Barbosa 2 \\ Amena A. Ferraz 4 \\ Marisa B. Cesarino 4
}

\footnotetext{
1 Pontifícia Universidade Católica de São Paulo, São Paulo, Brasil.

2 Faculdade de Medicina de São José do Rio Preto, São José do Rio Preto, Brasil.

3 Superintendência de

Controle de Endemias,

São José dos Campos, Brasil.

4 Secretaria Municipal

de Saúde e Higiene

de São José do Rio Preto,

São José do Rio Preto, Brasil.

Correspondência F. Chiaravalloti Neto Faculdade de Medicina de São José do Rio Preto. Rua Benjamin Constant 3741, apto. 77 ,

São José do Rio Preto, SP

15015-600, Brasil.

fcneto@famerp.br
}

\begin{abstract}
The aim of this article was to identify daily situations experienced by dengue control agents in their relationship to local residents. A cross-sectional study applied questionnaires among vector control agents, community health workers, and a sample of local women. The answers by the dengue control agents and community health workers were grouped in the categories of work, private life, and community. The women were asked about the relationship with the vector control and community health workers. The difficulties cited in the private and work areas by the vector control agents were different from those reported by community health workers. At the community level they coincided and showed that neither group is adequately prepared to deal with these issues. Of the local women interviewed, $87.0 \%$ reported that they were well-informed or very well-informed about dengue, $84.0 \%$ stated that the work by the vector control agents and community health workers was always helpful, and 54.0\% identified inappropriate visiting hours by vector control agents and community health workers as a difficulty. The study identified the need for a new job profile that would recognize and respect the specificities of the areas where their activities are conducted, integrating the community's socio-environmental issues.
\end{abstract}

Dengue; Vector Control; Community Health Agent; Health Education

\section{Introdução}

O número de casos de dengue e dengue hemorrágico tem apresentado tendência ascendente nos últimos anos 1, sendo vários os desafios colocados ao controle desta endemia. Uma primeira questão é que ainda predominam no Brasil os modelos médico-assistencialista e assistencial-sanitarista em Saúde Púbica 2 e a promoção da saúde que, segundo a Carta de Ottawa, é "o processo de capacitação da comunidade para atuar na melhoria da qualidade de vida e saúde, incluindo uma maior participação no controle deste processo" 3 (p. 678), só ocorrerá efetivamente a partir de alterações no sistema de saúde vigente.

Neste modelo, as atividades de vigilância e controle das doenças estão restritas às ações intra-setoriais do setor saúde 2 e não se tem privilegiado a prevenção, entendida como a atuação sobre os riscos de acontecer um evento não desejado e a antecipação das ações deslocando-se o foco da doença para a saúde 4.

Um exemplo a ser citado é a relação mantida entre os agentes responsáveis pelo controle de vetores e a população, que reconhece no agente uma porta de entrada para efetuar reclamações sobre a atuação do poder público, e requerer a resolução de problemas que vão além da presença do mosquito Aedes aegypti e da vulnerabilidade frente à doença 5 . Observa-se que o hiato entre o atendimento às demandas e a 
atuação do poder público promove um crescente descrédito da população em relação às competências do agente, o que interfere diretamente na sua atuação $5,6,7$.

Num contexto em que as campanhas de controle e prevenção apresentam caráter emergencial, e por vezes paliativo, aliado a ações antes fiscalizadoras que educativas, o agente enfrenta problemas no repasse do conhecimento técnico à população, deixando-o predisposto a represálias, especialmente por parte dos estratos sociais privados dos serviços de saúde, saneamento básico, educação e lazer 8,9.

A participação dos municípios no controle do dengue no Estado de São Paulo iniciou-se a partir da implantação do Plano de Emergência para Controle dos Vetores da Dengue e Febre Amarela, no verão de 1991/1992, com a constituição de equipes de agentes de controle de vetores que têm a função de executar visitas diárias aos domicílios e retirar e/ou eliminar criadouros do A. aegypti e realizar orientação à população ${ }^{10}$. A partir de 2002, estes agentes passaram a contar com a colaboração dos agentes comunitários de saúde do Programa Saúde da Família (PSF), estabelecida por meio da Portaria $n$. 44/GM de 2002 do Ministério da Saúde (http://dtr2001.saude.gov.br/bvs/popup/leg/ portarias_psf/portaria_n44_2002.pdf, acessado em 05/Abr/2004), que passaram a orientar sobre a prevenção e controle do dengue aos moradores visitados.

Estudos realizados mostraram níveis bastante elevados quanto ao grau de conhecimento da população do município e da região sobre dengue e seu vetor 11,12. Outro fator positivo ocorrido nos dois últimos anos foi o aumento da efetividade das atividades de controle, com o conseqüente declínio nas incidências de dengue. Em São José do Rio Preto, São Paulo, o coeficiente de incidência foi de $1.735,97$ casos por 100 mil habitantes em 2001, de 259,63, em 2002, e de 128,44, em 2003. Mas apesar dos esforços, a infestação por A. aegypti permanece em níveis elevados e a transmissão de dengue continua a ocorrer de maneira importante na região (Centro de Vigilância Epidemiológica, Secretaria de Saúde do Estado de São Paulo; dados não publicados).

Na expectativa de reverter essa situação, pensa-se em tratar o problema de forma mais integrada entre os órgãos responsáveis, direta e indiretamente. Também, tem-se dispensado maior atenção às particularidades das comunidades, contextualizando-as à luz das questões ambientais consoantes ao processo de urbanização 13,14, que muitas vezes contribui para o desequilíbrio das cidades, especialmente aquelas de médio e grande porte 15,16.

Assim, alia-se o problema da dengue às categorias ambiente - cidade - qualidade de vida 17 , estando esta última inscrita no processo de construção da cidadania e da garantia dos direitos, especialmente os relativos à saúde, saneamento básico, habitação e educação ${ }^{18}$. Da mesma forma, as categorias ambiente e cidade impõem a discussão sobre o cenário que envolve a vida das populações no ecossistema urbano, onde o processo de urbanização contribui muitas vezes para o seu desequilíbrio. $\mathrm{O}$ problema do dengue é um dos componentes deste quadro 15,16 , especialmente a persistência do vetor no meio urbano, que pode contribuir para a ocorrência de epidemias.

Desta maneira, o objetivo deste trabalho foi o de identificar, no contexto da atuação dos agentes responsáveis pelo controle do dengue em São José do Rio Preto, e na sua relação com os moradores, dificuldades, facilidades e situações comumente vivenciadas no dia-a-dia do desempenho de suas funções e discutir, a partir daí, formas de atuação integradas às questões sócio-ambientais das comunidades.

\section{Material e métodos}

A cidade de São José do Rio Preto está localizada a noroeste do Estado de São Paulo, compreende uma área de $575 \mathrm{~km}^{2}$ e tinha uma população estimada de 382.500 habitantes para 2003 (Departamento de Informação e Informática do SUS. Informações Demográficas. http:// tabnet.datasus.gov.br, acessado em 01/Out/ 2003). A Secretaria Municipal de Saúde e Higiene mantém a Equipe Municipal de Controle do Dengue, composta por 250 agentes de controle de vetores e 14 supervisores. A equipe atende cerca de 140 mil domicílios e realiza atividades de controle de criadouros de A. aegypti (casaa-casa), aplicação de inseticidas (pulverização) e visita e controle a locais com grande concentração de criadouros como borracharias, ferrosvelhos etc. (ponto estratégico). Também participam das atividades de controle do dengue os 33 agentes comunitários de saúde do PSF, implantado em 1997, e que atende atualmente a $6,0 \%$ das famílias do município.

Os objetivos propostos foram atingidos com a utilização de uma metodologia de natureza 
quantitativa. Dentro desta perspectiva foi realizado um estudo descritivo de corte transversal com aplicação de questionários à população dos agentes de controle de vetores e seus supervisores (grupo dos agentes de controle de vetores - ACV), à população dos agentes comunitários de saúde (grupo dos agentes comunitários de saúde - ACS) e a uma amostra da população de mulheres residentes no município. Os dados obtidos para os agentes de controle de vetores e seus supervisores foram analisados em conjunto, e estes são referidos no texto como grupos dos ACV ou simplesmente ACV.

Os grupos dos ACV e ACS foram abordados por meio de um mesmo questionário anônimo e auto-responsivo composto por perguntas fechadas e abertas. Este foi elaborado com base na observação e acompanhamento do trabalho dos agentes pela equipe de pesquisadores e testado previamente à aplicação.

Os dois grupos (ACV e ACS) foram abordados sobre o trabalho de controle e prevenção do dengue quanto às dificuldades, facilidades, aspectos que o caracterizam, as condições favoráveis ou ideais, além de dados sócio-demográficos, satisfação e receptividade em relação ao morador.

A fim de obter uma compreensão do contexto de atuação dos dois grupos de agentes, os dados foram sistematizados em três categorias: conforme o âmbito particular, trabalho e coletivo. O primeiro, refere-se à participação do morador nas atividades de controle e prevenção do dengue no espaço de sua casa, e a relação imediata que este mantém com o agente. $\mathrm{O}$ segundo trata das situações relativas à estrutura, condições, relações e circunstâncias que permeiam a esfera do trabalho, além da capacitação profissional. O terceiro trata dos aspectos físico-sociais do bairro onde os agentes atuam, além da postura do morador diante dos problemas da coletividade. Exemplos de situações que caracterizam os âmbitos particular, trabalho e coletivo são listados respectivamente nas Tabelas 1, 2 e 3 .

As informações sobre as dificuldades e as facilidades presentes no desempenho das funções de ambos os agentes nos âmbitos particular, trabalho e coletivo foram coletadas a partir de questões abertas com obtenção de respostas não estimuladas. Cada agente apresentou até três respostas para as questões sobre dificuldades e facilidades, e uma resposta para as questões sobre as dificuldades encontradas em janeiro e fevereiro. Estas respostas foram codificadas e agrupadas posteriormente sob a rubrica dos três âmbitos indicados.

Num outro rol de questões foram relacionadas situações comumente vividas na maio- ria das vezes pelos agentes. Baseando-se nessa relação de situações apreciadas pelos agentes, obtiveram-se respostas estimuladas que permitiram caracterizar o dia-a-dia do trabalho, identificar situações consideradas como ideais e avaliar como eles são recebidos pelos moradores.

Após a aplicação dos questionários e a codificação das respostas abertas, os dados obtidos foram digitados em um banco de dados do programa Microsoft Excel. A tabulação também foi realizada neste programa com a obtenção de freqüências absolutas e relativas. Estas foram consideradas exatas uma vez que se trabalhou com o universo dos agentes, não sendo necessário o cálculo dos intervalos de confiança.

O tamanho da amostra de mulheres foi calculado em 383, considerando-se uma freqüência esperada de 50,0\%, um erro amostral de 5\% e um intervalo de confiança de $95 \%$. A partir de uma taxa esperada de não resposta de $20,0 \%$, o tamanho da amostra foi fixado em 479 mulheres. A amostragem foi por conglomerado em dois estágios, respeitando-se o critério de partição proporcional ao tamanho. Sortearam-se quarteirões com probabilidade proporcional ao tamanho e em cada quarteirão um número fixo de casas 19. Em cada casa sorteada entrevistou-se a mulher responsável pelo domicílio.

Essas entrevistas foram realizadas por meio de questionário com perguntas abertas e fechadas, testado e aplicado por equipe treinada, sendo identificados os obstáculos que interferem na relação entre as mulheres e os agentes, os avanços ocorridos até então, além de opiniões e sugestões. Após a codificação das respostas às perguntas abertas, os dados obtidos foram digitados e tabulados no programa Microsoft Excel. Foram obtidas as freqüências absolutas e relativas com o cálculo dos respectivos intervalos de $95 \%$ de confiança, realizados usando-se o programa Epi Info 2002.

O projeto de pesquisa cumpriu todas as exigências do Comitê de Ética e Pesquisa da Faculdade de Medicina de São José do Rio Preto, com o fornecimento de termos de consentimento livre e esclarecido, assegurando aos entrevistados o sigilo de suas informações e para que os mesmos tivessem ciência do trabalho e de seus objetivos.

\section{Resultados}

Os questionários foram aplicados aos grupos dos ACV e ACS em março de 2004. Participaram da pesquisa 243 agentes de controle de vetores, seus 14 supervisores e 29 agentes comunitários 
Situações vividas na maioria das vezes pelos agentes de controle de vetores (ACV) e seus supervisores, e agentes comunitários de saúde (ACS) no desenvolvimento de suas atividades no âmbito particular. São José do Rio Preto, São Paulo, Brasil, 2003.

\begin{tabular}{|c|c|c|}
\hline Situação & $\mathrm{ACV}(\%)$ & $\operatorname{ACS}(\%)$ \\
\hline Recolher criadouros do quintal do morador e das calçadas & 85 & 3 \\
\hline Problemas com cão solto & 78 & 34 \\
\hline Realizar pelo morador aquilo que deveria ser feito por ele & 75 & 14 \\
\hline Má vontade do morador em receber o agente & 54 & 24 \\
\hline Presença de lixo nos quintais e calçadas & 51 & 59 \\
\hline Ter de eliminar criadouros que são considerados material útil para o morador (reciclador) & 38 & 31 \\
\hline Ter de falar com pessoas com distúrbios psicológicos & 7 & 21 \\
\hline
\end{tabular}

Tabela 2

Situações vividas na maioria das vezes pelos agentes de controle de vetores (ACV) e seus supervisores, e agentes comunitários de saúde (ACS) no âmbito do trabalho. São José do Rio Preto, São Paulo, Brasil, 2003.

\begin{tabular}{lcc}
\hline Situação & ACV (\%) & ACS (\%) \\
\hline Presença constante do serviço nas casas das pessoas & 79 & 59 \\
Repetição de informações & 71 & 47 \\
Problemas de percurso de sua casa até a área onde trabalha & 46 & 31 \\
Muita informação para repassar para o morador de uma só vez & 42 & 69 \\
Muito cansativo fisicamente & 26 & 59 \\
Ter de resolver outros problemas além daqueles relacionados a vetores ou ao dengue & 25 & 21 \\
Realizar atividades perigosas (subir na laje, limpar calha ou caixa d'água) & 16 \\
Condições precárias de trabalho (equipamento, mostruário, acessórios etc.) & 14 & 13 \\
Dificuldade de ter o mostruário sempre à mão & 46 \\
Falta de apoio das chefias para discutir os problemas do campo & 14 \\
Dificuldade de transporte ou locomoção, dentro da área de trabalho & 2 \\
Problemas com o preenchimento de boletins & 10 \\
\hline
\end{tabular}

Tabela 3

Situações vividas na maioria das vezes pelos agentes de controle de vetores (ACV) e seus supervisores, e agentes comunitários de saúde (ACS) no âmbito do coletivo. São José do Rio Preto, São Paulo, Brasil, 2003.

\begin{tabular}{lcc}
\hline Situação & ACV (\%) & ACS (\%) \\
\hline Problemas com casas fechadas & 76 & 52 \\
Problemas com casas vazias & 60 & 52 \\
Problemas com terrenos baldios & 61 & 69 \\
Problemas com outros insetos, ratos, animais peçonhentos & 28 & 38 \\
Ter de resolver desentendimentos entre vizinhos (discórdia, denúncia, rixa) & 18 & 17 \\
Problema com a coleta municipal de lixo & 11 & 14 \\
Problemas com drogas, violência etc., na área onde atua & 38 \\
\hline
\end{tabular}


de saúde. Os agentes que não participaram da pesquisa estavam de férias ou licença saúde no momento de sua realização. Assim, o grupo dos ACV constituiu-se de 257 entrevistados e o dos ACS de 29. Os dados coletados indicaram que a maioria dos agentes era do sexo feminino $(73,0 \%$ dos ACV e 90,0\% dos ACS). Dos ACV, 63,0\% tinham o ensino médio completo ou mais, $30,0 \%$ tinham o ensino médio incompleto ou o fundamental completo e $7,0 \%$ tinham o fundamental incompleto. Entre os ACS, 34,0\% tinham o ensino médio ou mais, $52,0 \%$ o ensino médio incompleto ou fundamental completo e $14,0 \%$ o fundamental incompleto.

As respostas não estimuladas dadas pelos agentes sobre as dificuldades e facilidades encontradas no desempenho de suas atividades foram categorizadas nos âmbitos particular, trabalho e coletivo, conforme definido em $\mathrm{Ma}$ terial e Métodos, e são apresentadas na Tabela 4. Os ACV citaram uma maior quantidade de dificuldades no âmbito particular, seguidas pelas dificuldades no coletivo e no trabalho. Para os ACS, as dificuldades cresceram no sentido do âmbito do trabalho para o particular e culminaram no coletivo. Observaram-se algumas diferenças no teor das dificuldades apontadas por ambos os agentes. No âmbito do trabalho, enquanto os ACV citaram espontaneamente como principais dificuldades a precariedade nas condições e nos materiais de trabalho e a presença constante do serviço nas casas, os ACS citaram o período das chuvas nos meses de janeiro e fevereiro e o horário de desenvolvimento das atividades.

No âmbito particular, os ACV citaram espontaneamente como principais dificuldades as recusas, os cães soltos e o descaso da população, enquanto os ACS, além destes, citaram o desconhecimento por parte da população sobre a gravidade da doença. As dificuldades no âmbito coletivo tiveram total coincidência no teor das respostas dos dois grupos de agentes: casas fechadas, abandonadas e em construção; terrenos baldios; e problemas com o lixo.

Após a categorização das respostas espontâneas sobre as facilidades, notou-se que os resultados foram semelhantes para ambos os agentes, e as freqüências apresentaram-se num sentido crescente do coletivo para o particular e trabalho (Tabela 4). No âmbito coletivo, enquanto os ACV citaram o acesso aos locais de trabalho, os ACS indicaram a participação de crianças, adolescentes e associações de bairro. No particular, ACV e ACS citaram como principal facilidade a aderência às praticas pelos moradores. No trabalho, os ACV indicaram o trabalho setorizado, o repasse de informações, o trabalho em equipe e as condições favoráveis de trabalho; os ACS também indicaram o trabalho setorizado e o seu perfil para atuar de forma específica no campo da saúde da família. Para ambos os grupos de agentes, as porcentagens para as dificuldades e facilidades do trabalho e do particular apresentam valores importantes. No âmbito coletivo se destacaram apenas as dificuldades.

Ao tratar especificamente dos meses de janeiro e fevereiro, os grupos atribuíram espontaneamente grande parte das dificuldades ao âmbito do trabalho (61,0\% para os ACV e $82,0 \%$ para os ACS), seguido pelo particular (16,0\% para os $A C V$ e $7,0 \%$ para os ACS) e coletivo $(9,0 \%$ para os ACV e 7,0\% para os ACS). As principais dificuldades citadas foram a ocorrência de chuvas, a pouca aderência às práticas pelos moradores, o aumento do número de criadouros e de larvas, o período de férias e festas e o aumento do número de casas fechadas, e a presença constante de serviço nas casas.

A caracterização do dia-a-dia do trabalho do agente, realizada a partir da apresentação de uma lista de situações aos agentes, seguiu a mesma categorização utilizada para as respostas espontâneas, isto é, os âmbitos particular, trabalho e coletivo. Os resultados são apresen-

Dificuldades e facilidades apontadas pelos agentes de controle de vetores (ACV) e seus supervisores, e pelos agentes comunitários de saúde (ACS) no desenvolvimento de suas atividades segundo os âmbitos do trabalho, particular e coletivo. São José do Rio Preto, São Paulo, Brasil, 2003.

\begin{tabular}{lcccc}
\hline Âmbito & \multicolumn{2}{c}{ ACV } & \multicolumn{2}{c}{ ACS } \\
& Dificuldades (\%) & Facilidades (\%) & Dificuldades (\%) & Facilidades (\%) \\
\hline Coletivo & 61 & 17 & 72 & 10 \\
Particular & 69 & 52 & 62 & 48 \\
Trabalho & 50 & 76 & 45 & 76 \\
\hline
\end{tabular}


tados respectivamente nas Tabelas 1, 2 e 3 . Comparando-se as respostas dadas pelo grupo dos ACV com as dos ACS não foi observado um comportamento único. Ocorreram desde total concordância até total discordância nos valores observados. Há maior discordância no trabalho e, em menor intensidade, no particular. No âmbito coletivo há coincidência nas respostas dadas pelos dois grupos de agentes em relação aos problemas enfrentados.

Para a realização do trabalho, os dois grupos de agentes identificaram como ideais algumas situações: a participação do morador na realização dos procedimentos e das práticas preventivas e a sua receptividade; o desejo de morar próximo à área de atuação e retornar sempre nas mesmas casas, especialmente os $\mathrm{ACV}$; conhecer os hábitos das famílias, ter mais conhecimento sobre outros problemas vividos pelo morador, além daqueles relativos ao dengue; buscar mais informações sobre o assunto dengue; e conhecer os problemas da área onde atuam.

Responderam ao questionário 348 mulheres residentes no município, com idades entre 16 e 66 anos. Apesar das casas sorteadas terem sido visitadas por até três vezes, a taxa de não resposta foi de $27,0 \%$ gerando um tamanho de amostra menor do que o esperado. Cerca de 38,0\% (IC95\%: 33-43) das mulheres julgaram ter aprendido tudo com o agente, 49,0\% (IC95\%:
43-54) bastante, e apenas 4,0\% (IC95\%: 2-6) julgaram ter aprendido pouco ou nada. O mesmo se verifica em relação ao grau de informação, quando 29,0\% (IC95\%: 25-34) delas alegaram estar muito bem informadas e 58,0\% (IC95\%: 53-63), bem informadas. Na perspectiva das mulheres sobre o desempenho dos agentes no seu trabalho, 90,0\% (IC95\%: 86-93) consideraram os agentes dispostos ou muito bem dispostos.

Entre as entrevistadas, 39,0\% (IC95\%: 3444) não indicaram situações difíceis para atender o agente, 54,0\% (IC95\%: 49-59) apontaram dificuldades no seu dia-a-dia e citaram o horário como impróprio à visita; o fato de estar fora ou de saída, coincidindo com a chegada do agente; estar ocupada no momento da visita; ter de prender os cães; visitas no final de semana; e as visitas durante a semana. A falta de segurança, presente em 3,0\% (IC95\%: 1-5) das repostas, foi relacionada ao atendimento a agentes masculinos.

As entrevistadas indicaram as atividades que consideram mais importantes e mais eficientes no combate ao dengue, e também aquelas que poderiam ser realizadas pelos agentes futuramente (Tabela 5), tais como: repasse de informação e orientação; fiscalização, vistoria e notificação - atividades rotineiras e que caracterizam o trabalho de controle, configurado-se assim incoerência e/ou falta de informa-

Opinião das mulheres entrevistas (em porcentagens e respectivos intervalos de confiança de 95\%) em relação às atividades mais importantes entre as realizadas pelos agentes, as que poderiam ser desenvolvidas futuramente e as mais eficientes no combate ao dengue. São José do Rio Preto, São Paulo, Brasil, 2003.

\begin{tabular}{|c|c|c|c|}
\hline Atividades & Mais importantes (\%) & $\begin{array}{l}\text { Que poderiam } \\
\text { ser realizadas } \\
\text { futuramente }(\%)\end{array}$ & Mais eficientes (\%) \\
\hline Não tem & 0 * & $50(45-55)$ & $2(1-4)$ \\
\hline Informação e orientação & $34(29-39)$ & $3(1-5)$ & $8(5-11)$ \\
\hline Fiscalização, vistoria, notificação & $27(22-35)$ & $4(2-7)$ & $12(9-16)$ \\
\hline Atividades de rotina & $8(5-11)$ & $1(0-3)$ & $0 *$ \\
\hline Cuidado com os criadouros & $8(5-11)$ & $0^{*}$ & $7(4-10)$ \\
\hline Uso de produtos e de medidas convencionais & $7(4-10)$ & $6(4-9)$ & $15(11-19)$ \\
\hline Atividades de cuidado com a água & $3(1-5)$ & $0 *$ & $19(15-23)$ \\
\hline $\begin{array}{l}\text { Atividades relativas ao cuidado com a casa } \\
\text { (interior e quintal) }\end{array}$ & 0 * & $2(1-4)$ & $12(9-16)$ \\
\hline Conscientização e trabalho em conjunto & $0 *$ & $3(1-5)$ & $10(7-14)$ \\
\hline Cuidado com os criadouros do bairro & $0^{*}$ & $9(6-12)$ & $7(4-10)$ \\
\hline Outros & $13(10-17)$ & $22(18-27)$ & $8(5-11)$ \\
\hline Total & 100 & 100 & 100 \\
\hline
\end{tabular}

* Intervalo de $95 \%$ de confiança indeterminado. 
ção por parte das entrevistadas, aspecto a ser considerado pelo serviço e indicação de que o seu público-alvo não está sendo atingido.

Numa avaliação sobre as visitas, $84,0 \%$ (IC95\%: 80-88) das mulheres julgaram se tratar de um trabalho que ajuda sempre, contra $1,0 \%$ (IC95\%: 0-3) que julgou que nunca ajuda ou ajuda em quase nada. A importância das visitas reside, segundo as mulheres, na informação que os agentes passam, no combate à doença $\mathrm{e}$ no ato de fiscalização. Das mulheres, 84,0\% (IC95\%: 80-88) afirmaram não ter dúvidas sobre o trabalho e o dengue, em detrimento de outras 10,0\% (IC95\%: 7-14) que não se sentiram bem informadas, especialmente, quanto à doença, sintomas e exames, e sobre o dengue hemorrágico. Persistiram dúvidas sobre as medidas preventivas e de controle, sobre o uso de inseticidas e de medidas alternativas, e sobre o vetor e sua identificação.

\section{Discussão}

Para Tauil 20, as limitações das atividades de controle são ocasionadas pela própria estrutura de contratação, supervisão, abrangência e educação. As dificuldades relacionadas pelos ACV e ACS apresentaram maiores freqüências nos campos particular e coletivo, que constituem facetas de uma mesma situação que requer a presença dos atores envolvidos para ser equacionada. Para o primeiro grupo persistiu a crônica falta de aderência da população, e para o segundo despontaram os problemas de bairro que escapam à sua atribuição. A participação dos moradores pode ocorrer tanto no âmbito de sua residência como diante dos problemas da comunidade, e o serviço deve estar presente e fornecer suporte técnico aos agentes, para que eles estejam aptos a encaminhar as demandas recebidas pelos moradores.

Penna 21 constatou que o problema do dengue envolve população e autoridades e que é necessário pensar na contribuição de moradores como efetiva e permanente. No entanto, para que isto aconteça, é necessária a reavaliação das formas de repasse de informações, bem como do trabalho dos agentes responsáveis pelo controle de vetores, uma vez que a população, apesar de bem informada, não dá continuidade às práticas pela repetição exaustiva das mesmas sem novos elementos, e também por caracterizarem as medidas preventivas como infrutíferas ou mesmo impossíveis de serem adotadas, considerando as medidas curativas mais importantes 22. Para Chiaravalloti Neto et al. 12 , é importante romper a tentativa de alterar as práticas por meio da divulgação de mensagens, mas com a estruturação de trabalhos que respeitem o conhecimento da população e as prioridades. Esta precisa receber informações recentes, ter um elo de comunicação com os agentes responsáveis pelo controle de vetores, e conseqüentemente com o governo, que precisa fornecer os meios adequados para a ocorrência de práticas, como coleta de lixo, suprimento contínuo de água, cuidados com o espaço público e informação adequada sobre os riscos, produtos e serviços disponíveis 21 .

Os ACS conseguem desempenhar de forma mais satisfatória suas atribuições que os ACV, pois estes enfrentam com maior freqüência problemas que extrapolam as suas atribuições. As recusas são contornadas por algumas equipes de ACV com a implantação do trabalho setorizado, que visa a estreitar o vínculo entre agente e morador, diminuindo a sua resistência e aumentando o grau de entendimento sobre a dinâmica do trabalho (Baglini V; dados não publicados). Em avaliação feita na cidade de Catanduva, São Paulo, apesar das mulheres mostrarem-se receptivas à visita domiciliar, foi constatada queixa importante sobre a ausência do vínculo entre serviço e morador, ilustrado pelo rodízio de agentes, o que segundo elas prejudica $o$ andamento do trabalho 5 .

Chama a atenção a referência feita pelos ACS sobre a importância da coletividade por meio da participação de associações de bairro, da igreja e de crianças e adolescentes, que se configuram num canal de comunicação que poderia favorecer a relação entre o serviço e o morador e aumentar a adesão ao trabalho. Segundo Chiaravalloti Neto el al. 12, a educação em saúde não depende apenas da orientação de pessoas, mas também do seu envolvimento para que se responsabilizem por ações, executando as que lhe competem, e o conhecimento de suas prioridades para que exista entre o serviço e a população uma relação de colaboração. A baixa incidência com que estes fatores foram apontados revela o seu potencial pouco explorado para a prevenção, e reitera a prática de caráter individual tanto do serviço como da própria população.

A análise das principais respostas dadas pelos agentes para as facilidades encontradas dá indícios de como poderia ser o trabalho de um agente com um novo perfil. O primeiro é a necessidade de formação de agentes para atuarem no âmbito coletivo; outro, é o trabalho setorizado, por facilitar o vínculo entre agente e morador, e, por fim, a própria característica do ACS, cujo perfil e tipo de atividade estão voltados para as questões específicas de saúde da 
família e do estreito vínculo que isso requer. Chiaravalloti Neto et al. 12 constataram a necessidade de mudança no perfil de agente responsável pelo controle de dengue. Observa-se também que os órgãos de saúde devem procurar novas estratégias, como as campanhas educativas baseadas na organização e conhecimentos das comunidades, interferência sobre as fontes produtoras de recipientes descartáveis e adoção de políticas públicas que privilegiem o saneamento ambiental 23.

As respostas sobre as situações vividas pelos agentes mostraram algumas diferenças entre ACV e ACS. Para os ACV é freqüente no âmbito particular o "recolhimento pelo agente de criadouros do quintal dos moradores e das calçadas", situação pouco citada pelos ACS. Este comportamento vai contra a atuação pretendida para um novo agente, pois esbarra no pressuposto de uma participação mais ativa do morador nas práticas preventivas. Winch et al. 24 constataram que este tipo de atividade não incentiva a população a realizar ela mesma as atividades de controle de vetores no seu domicílio. Por outro lado, estudo realizado sobre as práticas preventivas do dengue mostrou que as mulheres preferem cuidar elas próprias dos criadouros em suas casas 5, abrindo espaço para a revisão do papel do agente.

Apesar da atuação diferenciada entre os agentes, eles sofrem de problemas comuns como a "disposição do lixo" e a "eliminação de criadouros úteis" ou materiais reciclados que implicam criadouros em potencial, que poderiam ser minimizados a partir da busca de soluções conjuntas entre agente e morador e de soluções integradas pelo poder público. Segundo Chiaravalloti Neto et al. 12, nem todos os materiais presentes no domicílio são sem utilidade, pois serão potencialmente utilizáveis em algum momento para venda ou doação.

No âmbito do trabalho, "a presença constante nas casas" e a "repetição de informações" com altas freqüências para os ACV demonstraram o caráter repetitivo da atividade e a necessidade de mudanças, situação constatada também por Chiaravalloti Neto et al. 12. As diferenças entre as freqüências apresentadas pelos ACV e ACS para "resolução de outros problemas", "realização de atividades perigosas" e "dificuldades de transporte” estão associadas e diretamente relacionadas ao perfil de cada trabalhador e deverão ser levadas em conta na formação do novo agente.

Também houve coincidência sobre os problemas enfrentados pelos ACV e ACS no coletivo, o que confirma que eles não estão preparados para atuar neste âmbito. Outra razão para estabelecer um novo perfil para o agente, que o torne capaz de encaminhar demandas originadas na comunidade, desde que observado o suporte técnico necessário. Winch et al. 24 observaram que a participação das comunidades no delineamento e encaminhamento de soluções para os problemas de saúde pública oferecem vantagens se comparadas aos programas tradicionais de controle de dengue.

Da análise das ações relacionadas como ideais, nota-se a intenção por parte dos agentes em atingir maior resolutividade das ações de controle e prevenção ao dengue a partir de uma atuação que respeite a dinâmica própria da localidade onde atuam. Daí o destaque dado ao conhecimento sobre os hábitos familiares, da comunidade, além do conhecimento técnico, enquanto elementos constitutivos do trabalho preventivo.

A afirmação da necessidade da participação do morador na realização dos procedimentos e das práticas preventivas, e de uma melhor receptividade demonstram o quanto é importante para o agente a sensibilização da população para a problemática do dengue e da importância dada ao seu trabalho. Chiaravalloti et al. 5 constataram que uma das principais demandas colocadas pelas moradoras é a busca de uma nova relação entre agentes e população, onde caberá ao agente o papel de orientador e não de fiscalizador.

O desejo de morar próximo à área de trabalho e retornar sempre às mesmas casas, especialmente no caso dos ACV, implica a verificação da disponibilidade destes agentes conforme as áreas de atuação. Se para os ACS esse aspecto já é uma premissa para o trabalho, no caso dos ACV há controvérsias quanto à real efetividade da medida, dada a possibilidade de ocorrer desvios na função e interferir na qualidade final do seu trabalho (Baglini V; dados não publicados).

Quanto às dificuldades relatadas pelas mulheres no atendimento dos agentes, verifica-se um descompasso na conjugação das expectativas entre morador e agente, e isso ocorre especialmente com os ACV, pois os ACS atuam em uma área muito restrita do município. Observa-se que a dificuldade de recepção do morador esbarra no campo de atuação do agente, pois as recusas e a má vontade vindas do primeiro nada mais representam do que a intenção em garantir certa privacidade no âmbito particular, pois o caráter fiscalizador é ainda o principal fator de distensão entre eles. As reclamações feitas pelas mulheres sobre as interferências das visitas em seu dia-a-dia são reflexo da aplicação de medidas homogeneizadoras, 
daí a necessidade de equalizar as atividades dos agentes às realizadas pelas donas-de-casa, no sentido de conquistar maior adesão. Para Chiaravalloti Neto et al. 12 , as visitas domiciliares deveriam ser melhor aproveitadas para um relacionamento mais aprofundado entre os funcionários responsáveis pelo controle de vetores e os moradores.

A confusão observada em relação às atividades que as mulheres gostariam que fossem realizadas futuramente, mas que já o são, denotam falta de discernimento quanto ao conteúdo destas, podendo indicar falha por parte do serviço no repasse da informação, o que compromete ainda mais o grau de aderência tão almejado. Por fim, há o desejo das entrevistadas em relação à realização de atividades coletivas no próprio bairro.

\section{Conclusões}

A questão levantada pela realidade do município é a emergência de um profissional apto a reconhecer e respeitar as particularidades dos locais onde atua, como expressão da integração entre os órgãos responsáveis, em consonância com as transformações ocorridas no espaço urbano, onde o dengue é mais um fator de desequilíbrio. As observações presentes no estudo fornecem alguns subsídios para a adequação do agente à atual realidade em que atua e para a contextualização de seu trabalho de forma mais efetiva, com uma conseqüente melhoria não só no controle de vetores, mas de seu papel perante a comunidade, como um sujeito importante na sua área de atuação e não simplesmente como um fiscalizador que não oferece resoluções práticas aos problemas que encontra, com função estéril perante a comunidade. Isso se apresenta ao serviço como uma grave contradição, em que a reciprocidade entre agente e morador, aspecto fundamental na prevenção do dengue, vem sendo desgastada.

Uma intervenção integrada dos órgãos responsáveis seria o ponto de partida para o entendimento do caráter multidisciplinar do dengue, pois estando as atividades de controle ligadas à promoção da saúde, não há como dissociá-las de outras questões como educação, saneamento básico, condições de moradia, melhorias e manutenção do espaço público. São estas as que resultam em demandas que recaem sobre o cotidiano dos agentes, sendo necessário formar um agente apto a discorrer sobre a promoção da saúde, a partir do controle de endemias.

Verifica-se por parte dos agentes o desejo em obter subsídios para o desempenho de novas funções, da mesma forma que existe clareza quanto às responsabilidades que adviriam desta nova conduta. Trata-se de um movimento que se conjuga aos objetivos deste trabalho, o de discutir o papel do agente, e cujo sucesso depende em princípio da concordância do grupo, daí ouvir as vozes dissonantes, e especialmente de um programa de capacitação e formação sobre as questões sócio-ambientais da comunidade.

Uma vez que o problema do dengue extrapola cada vez mais os limites da atuação individualizada de cada morador e requer uma ação coletiva, delineia-se uma preocupação em incorporar na atuação do agente um olhar particularizado em relação aos aspectos peculiares dos grupos que compõem a população. O incentivo à participação de grupos, associações de bairro e de escolas poderia ser um aliado ao serviço de controle, atrelando a prevenção às práticas associativistas. De atuações conjuntas entre Estado e população adviria uma compreensão maior sobre a prevenção como forma de atenuar o perigo iminente da doença. A conquista de maior participação da comunidade poderia vir com a implantação do sistema setorizado como forma de estreitar o vínculo do agente com o morador e diminuir o número de recusas, inibir práticas de descaso, além de construir práticas de cooperativismo, a partir do envolvimento do morador com o trabalho do agente.

Porém, não basta apenas um agente com novo perfil para solucionar os problemas de falta de aderência da população às práticas preventivas. A sua solução passa pela definição dos princípios que fundamentam a atuação do poder público no campo do controle das endemias. Por um lado, esta equação pressupõe uma revisão sobre o afastamento do Estado nas últimas décadas de suas funções na área social e, neste caso, uma necessária reaproximação. Por outro, o poder público deve adequar a sua máquina para uma ação integral, de modo que suas atribuições sejam desenvolvidas sob a ótica da inter-setorialidade. 


\section{Resumo}

O objetivo foi identificar, no contexto da atuação dos agentes responsáveis pelo controle do dengue e na sua relação com moradores, situações vivenciadas no diaa-dia de suas funções. Realizou-se estudo transversal com aplicação de questionários à população dos agentes de controle de vetores (ACV), à dos agentes comunitários de saúde (ACS) e a uma amostra de mulheres. As respostas dadas pelos agentes foram agrupadas nos âmbitos do trabalho, particular e coletivo. As mulheres foram abordadas sobre a relação mantida com os agentes. As dificuldades citadas nos âmbitos particular e trabalho pelos ACV diferiram das citadas pelos ACS. No coletivo foram coincidentes e mostraram que ambos não estão preparados para lidar com estas questões. Das mulheres entrevistadas, 87,0\% afirmaram estar bem ou muito bem informadas sobre dengue, 84,0\% afirmaram que os trabalhos dos agentes ajudam sempre e 54,0\% apontaram como dificuldade o horário impróprio da visita realizada pelo agente. Identificou-se a necessidade de um novo profissional que reconheça e respeite as particularidades dos locais onde atua e desenvolva suas atividades de forma integrada às questões sócio-ambientais da comunidade.

Dengue; Controle de Vetores; Agente Comunitário de Saúde; Educação em Saúde

\section{Colaboradores}

V. Baglini contribuiu na elaboração, teste e supervisão da aplicação dos instrumentos de coleta de dados para as mulheres e os agentes, discussão dos resultados e redação do artigo. E. A. Favaro, A. C. Ferreira e A. Mondini participaram da elaboração, teste e aplicação do instrumento de coleta de dados para as mulheres, tabulação dos dados, discussão dos resultados e redação. F. Chiaravalloti Neto colaborou na elaboração do banco de dados, do processo de amostragem, análise estatística, discussão dos resultados e redação. M. R. Dibo, A. A. C. Barbosa, A. A. Ferraz e M. B. Cesarino colaboraram na elaboração, teste e aplicação do instrumento de coleta de dados para as mulheres, discussão dos resultados e redação.

\section{Agradecimentos}

Agradecemos a participação dos membros da Equipe Municipal de Controle do Dengue e do Programa Saúde da Família da Secretaria Municipal de Saúde e Higiene do município, a participação das mulheres entrevistadas, o apoio dos alunos do Centro Universitário de Rio Preto, de Marlene C. G. de Souza e de Sirle A. S. Scandar na aplicação dos questionários.

\section{Referências}

1. Tauil PL. Urbanização e ecologia do dengue. Cad Saúde Pública 2001; 17:99-102.

2. Machado JMH, Porto MFS. Promoção da saúde e inter-setorialidade: a experiência da vigilância em saúde do trabalhador na construção de redes. Epidemiol Serv Saúde 2003; 12:121-30.

3. Barbosa LMM. Glossário de epidemiologia e saúde. In: Rouquayrol MS, Almeida-Filho N, organizadores. Epidemiologia e saúde. Rio de Janeiro: Medsi; 2003. p. 649-90.

4. Augusto LGS. Saúde e vigilância ambiental: um tema em construção. Epidemiol Serv Saúde 2003; 12:177-87.

5. Chiaravalloti VB, Moraes MS, Chiaravalloti Neto F, Conversani DT, Fiorin AM, Barbosa AAC, et al. Avaliação sobre adesão às práticas preventivas do dengue: o caso de Catanduva, São Paulo, Brasil. Cad Saúde Publica 2002; 18:1321-9.

6. Giddens A. As conseqüências da modernidade. São Paulo: Editora Unesp; 1991.

7. Clark GG. Situacion epidemiologica el dengue en America. Desafios para su vigilancia y control. Salud Pública Méx 1995; 37:S5-11.

8. Oliveira RM, Valla VV. As condições e as experiências de vida de grupos populares no Rio de Janeiro: repensando a mobilização popular no controle do dengue. Cad Saúde Pública 2001; 17:77-88.

9. Valla VV. Participação popular e saúde: a questão da capacitação técnica no Brasil. In: Valla VV, Stotz $\mathrm{N}$, organizadores. Participação popular, educação e saúde. Teoria e prática. Rio de Janeiro: Relume-Dumará; 1993. p. 11-22.

10. Superintendência de Controle de Endemias. Plano de emergência para o controle dos vetores do dengue e da febre amarela no verão de 1991-1992 no Estado de São Paulo. São Paulo: Superintendência de Controle de Endemias; 1991.

11. Chiaravalloti Neto F, Moraes MS, Fernandes MA. Avaliação dos resultados de atividades de incentivo à participação da comunidade no controle do dengue em um bairro periférico de São José do Rio Preto, São Paulo, e da relação entre conhecimentos e práticas desta população. Cad Saúde Pública 1998; 14:101-11.

12. Chiaravalloti Neto F, Fiorin AM, Conversani DT, Cesarino MB, Barbosa AAC, Dibo MR, et al. Controle do vetor do dengue e participação da comunidade, São Paulo, Brasil. Cad Saúde Pública 2003; 19:1739-49.

13. Hogan DJ, Carmo RL, Cunha R, Tavolaro SBF. Um breve perfil ambiental do Estado de São Paulo. In: Hogan DJ, Cunha R, Baeninger R, Carmo RL, organizadores. Migração e ambiente em São Paulo: aspectos relevantes das dinâmicas recentes. Campinas: Núcleo de Estudos de População, Universidade Estadual de Campinas; 2000. p. 275-381.

14. Sposito MEB. As cidades médias e os contextos econômicos contemporâneos. In: Sposito MEB, organizador. Urbanização e cidades: perspectivas geográficas. Presidente Prudente: Editora Unesp; 2001. p. 569-607.

15. Cristopholetti A. Impactos no meio ambiente ocasionados pela urbanização tropical. In: Souza MAA, Santos M, Scarlato FC, Arroyo M, organizadores. 
Natureza e sociedade de hoje: uma leitura geográfica. São Paulo: Editora Hucitec/Associação Nacional de Pós-graduação e Pesquisa em Planejamento Urbano e Regional; 1994. p. 127-38.

16. Leite MAFP. A natureza e a cidade: rediscutindo suas relações. In: Souza MAA, Santos M, Scarlato FC, Arroyo M, organizadores. Natureza e sociedade de hoje: uma leitura geográfica. São Paulo: Editora Hucitec/Associação Nacional de Pós-graduação e Pesquisa em Planejamento Urbano e Regional; 1994. p. 139-45.

17. Souza GOC. Cidade, meio ambiente e modernidade. In: Sposito MEB, organizador. Urbanização e cidades: perspectivas geográficas. Presidente Prudente: Editora Unesp; 2001. p. 253-79.

18. Benevides MVM. 1994. Cidadania e democracia. Lua Nova 1994; 33:5-16.

19. Kish L. Survey sampling. Washigton DC: John Wiley \& Sons; 1967.
20. Tauil PL. Aspectos críticos do controle do dengue no Brasil. Cad Saúde Pública 2002; 18:867-71.

21. Penna MLF. Um desafio para a saúde pública brasileira: o controle do dengue. Cad Saúde Pública 2003; 19:305-9.

22. Winch P, Lloyd L, Godas MD, Kendall C. Beliefs about the prevention of dengue and other febrile illness in Mérida, México. J Trop Med Hyg 1991; 94:377-87.

23. Chiaravalloti Neto F. Conhecimentos da população sobre dengue, seus vetores e medidas de controle em São José do Rio Preto, São Paulo. Cad Saúde Pública 1997; 13:447-53.

24. Winch P, Kendall C, Gubler D. Effectiveness of community participation in vector-borne disease control. Health Policy Plan 1992; 7:1-9.

Recebido em 23/Set/2004

Versão final reapresentada em 08/Mar/2005

Aprovado em 14/Mar/2005 